\title{
Case Report: COVID-19 Misdiagnosed as a Drug Reaction to Miltefosine
}

\author{
Jaime A. Soto, ${ }^{1 *}$ María Isabel Méndez, ${ }^{2}$ and Jonathan D. Berman ${ }^{3,4}$ \\ ${ }^{1}$ Fundación Nacional de Dermatologia (FUNDERMA) y Hospital Dermatologico de Jorochito, Santa Cruz, Bolivia; ${ }^{2}$ Centro Nacional de \\ Enfermedades Tropicales (CENETROP), Santa Cruz, Bolivia; ${ }^{3}$ Fast-Track Drugs and Biologics LLC, North Potomac, Maryland; ${ }^{4}$ AB Foundation, \\ North Bethesda, Maryland
}

\begin{abstract}
We present case reports of two patients treated with miltefosine for mucocutaneous leishmaniasis whose gastrointestinal symptoms were initially diagnosed as a drug reaction and only later recognized as due to COVID-19. Gastrointestinal symptoms of COVID-19 are unusual, whereas gastrointestinal adverse drug reactions are very common. These reports exemplify that this infrequent presentation of COVID-19 is likely to be ascribed to a more common etiology such as a gastrointestinal drug reaction.
\end{abstract}

Perhaps the simplest way of showing how COVID-19 has upended routine life is to observe that as of February 23, 2021, the United States has experienced $27,938,083$ cases of the disease with 497,415 deaths. ${ }^{1}$ Although COVID-19 presents with fever, respiratory symptoms, body aches and fatigue, headache, loss of taste or smell, and sore throat and runny nose, the Center for Disease Control's list of symptoms also includes nausea/vomiting/ diarrhea at the end. ${ }^{1}$ Nausea/vomiting, diarrhea, and abdominal pain are thought to occur in $7.8 \%, 7.7 \%$, and $2.7 \%$ of COVID-19 cases, respectively. ${ }^{2}$ The similarity of the infrequent gastrointestinal symptoms of COVID-19 to the standard presentations of gastrointestinal diseases has led to COVID-19 being misdiagnosed as acute pancreatitis, ${ }^{3}$ appendicitis, ${ }^{4}$ acute surgical abdomen, ${ }^{5-7}$ mesenteric lymphadenopathy, ${ }^{8}$ abdominal pain, ${ }^{9,10}$ and epigastric discomfort and dyspepsia. ${ }^{11}$ Misdiagnosis of COVID-19 as a gastrointestinal adverse drug reaction (ADR) has apparently been less frequently reported.

\section{CASE REPORTS}

Patient 1, a 22-year-old male in his 12th day of treatment for cutaneous leishmaniasis with miltefosine, complained of severe nausea, occasional episodes of vomiting and abdominal pain, profuse sweating without fever, general malaise, and mild headache (Table 1). Because nausea, vomiting, and headache occur in $36 \%, 4.5 \%$, and $28 \%$ of miltefosine patients, respectively, ${ }^{12}$ adverse reactions to miltefosine were suspected and symptomatic management (metoclopramide and paracetamol) was instituted. However, the persistence of this clinical picture for 4 days led to laboratory tests which revealed a positive PCR test for SARS-CoV-2. The patient continued with the same management for five more days, and the symptoms subsided without stopping miltefosine.

Patient 2, a 56-year-old male in his third day of treatment for mucosal leishmaniasis with miltefosine, complained of severe nausea, headache, and episodes of vomiting and diarrhea(Table 1). $\mathrm{He}$ had a temperature of $38.3^{\circ} \mathrm{C}$ with profuse diaphoresis. The presumed adverse reaction to miltefosine was managed with domperidone and diclofenac, and miltefosine treatment was suspended. Because the patient's symptoms were judged not severe, miltefosine was restarted on day 5 , and symptomatic treatment was suspended on day 10 . On day 11 , laboratory testing revealed a

* Address correspondence to Jaime A. Soto, Fundación Nacional de Dermatologia (FUNDERMA) y Hospital Dermatologico de Jorochito, Santa Cruz, Bolivia. E-mail: jaime.soto@infoleis.com positive PCR for SARS-CoV-2. Symptoms essentially remitted on day 15 . The patient was able to complete the standard 28-day course of miltefosine.

\section{DISCUSSION}

The gastrointestinal tract is arguably the organ system most affected by ADRs: $21.6 \%$ of ADRs were referable to the gastrointestinal system. ${ }^{13}$ The most common drug reactions to miltefosine are gastrointestinal; however, there are also warnings conceming reproductive effects and renal and hepatic biochemical abnormalities. ${ }^{12}$ Because the gastrointestinal effects of COVID-19 can be misdiagnosed as gastrointestinal diseases, it is also likely that a gastrointestinal presentation of COVID-19 can be misdiagnosed as gastrointestinal ADRs. The concordance of nausea/vomiting/ diarrhea between COVID-19 symptoms and miltefosine ADRs speaks to the ease of confusing these two etiologies; however, for our two patients, it can be recognized in retrospect that diaphoresis is a common sign of COVID-19 infection but is not a miltefosine ADR. The disease for which our patients were treated, cutaneous leishmaniasis, does not have systemic manifestations and would not be confused either with an ADR or with COVID-19.

TABLE 1

Demographics and clinical course

\begin{tabular}{|c|c|c|}
\hline Parameter & Patient \#1 & Patient \#2 \\
\hline Age (years) & 22 & 56 \\
\hline Gender & Male & Male \\
\hline Concomitant diseases & No & No \\
\hline $\begin{array}{l}\text { Concomitant } \\
\text { medications }\end{array}$ & No & No \\
\hline $\begin{array}{l}\text { Day of milt RX } \\
\text { that SX began }\end{array}$ & 12 & 3 \\
\hline \multirow[t]{5}{*}{ Symptoms } & Nausea: severe & Nausea: severe \\
\hline & $\begin{array}{l}\text { Vomit/Abd pain: } \\
\text { occasional }\end{array}$ & $\begin{array}{l}\text { Vomit/diarrhea: } \\
\text { occasional }\end{array}$ \\
\hline & Sweating: profuse & Sweating: profuse \\
\hline & Febrile? no & Febrile: $38.3^{\circ} \mathrm{C}$ \\
\hline & $\begin{array}{l}\text { Headache: mild } \\
\text { Malaise: general }\end{array}$ & Headache \\
\hline Miltefosine stopped? & No & Yes: 2 days \\
\hline $\begin{array}{l}\text { Days symptomatic } \\
\text { treatment }\end{array}$ & $12-21^{*}$ & $3-10 \dagger$ \\
\hline $\begin{array}{l}\text { Day PCR (SARS-CoV-2) } \\
\text { results }\end{array}$ & 16 & 11 \\
\hline Day SX largely remit & 21 & 15 \\
\hline Milt course completed? & Yes & Yes \\
\hline
\end{tabular}


Although we have not been able to identify previous reports of the presentation of COVID-19 being mistaken as a gastrointestinal ADR, we suspect that confusion between COVID-19 and ADRs is not unusual. The incidence of COVID-19 is enlarging; for example, Bolivia, with a population of approximately $11,700,000,{ }^{14}$ had a total of 142,889 positive tests for COVID-19 as of November 12, 2020 but 210,726 positive cases as of January 28, 2021 with 10,226 deaths. Adverse drug reactions encompass more than just gastrointestinal symptoms. Fatigue represents $7.4 \%$ of ADRs; dizziness, 4.3\%; headache, 1.6\%; myalgia, $1.2 \%$; and cough, $2.3 \%{ }^{13}$; and all these are also symptoms of COVID-19. Our case reports of treatment of a parasitic disease illustrate the misdiagnosis of an infrequent manifestation of COVID as a common ADR. We suspect that COVID-19 and ADRs will also be confused inversely: the misdiagnosis of less common ADRs as common manifestations of COVID-19.

Received November 25, 2020. Accepted for publication February 26, 2021.

Published online March 11, 2021.

Acknowledgments: The American Society of Tropical Medicine and Hygiene has waived the Open Access fee for this article due to the ongoing COVID-19 pandemic.

Disclosure: J. D. B. is an employee of Fast-Track Drugs and Biologics, which has a contractual relationship with Knight Therapeutics, the NDA sponsor of Impavido (miltefosine). The manuscript was written pro bono.

Authors' addresses: Jaime A. Soto, Fundación Nacional de Dermatologia (FUNDERMA) y Hospital Dermatologico de Jorochito, Santa Cruz, Bolivia, E-mail: jaime.soto@infoleis.com. María Isabel Méndez, Centro Nacional de Enfermedades Tropicales (CENETROP), Santa Cruz, Bolivia, E-mail: mariamndez@hotmail.com. Jonathan D. Berman, Fast-Track Drugs and Biologics LLC, North Potomac, MD, E-mail: jberman@fasttrackresearch.com.

This is an open-access article distributed under the terms of the Creative Commons Attribution (CC-BY) License, which permits unrestricted use, distribution, and reproduction in any medium, provided the original author and source are credited.

\section{REFERENCES}

1. Centers for Disease Control and Prevention, 2020. COVID. Available at: https://www.cdc.gov/coronavirus/2019-ncov/index.html and at https://www.cdc.gov/coronavirus/2019-ncov/symptomstesting/symptoms.html. Accessed February 23, 2021.

2. Sultan $S$, Altayar O, Siddique SM, Davitkov $P$, Feuerstein JD, Lim JK, Falck-Ytter Y, El-Serag HB; AGA Institute, 2020. AGA institute rapid review of the gastrointestinal and liver manifestations of COVID-19, meta-analysis of international data, and recommendations for the consultative management of patients with COVID-19. Gastroenterology 159: 320-334.e27.

3. Purayil N, Sirajudeen J, Va N, Mathew J, 2020. COVID-19 presenting as acute abdominal pain: a case report. Cureus 12 : e9659.

4. Suwanwongse K, Shabarek N, 2020. Pseudo-appendicitis in an adolescent with COVID-19. Cureus 12: e9394.

5. Ahmed A, Badawi M, Ahmed K, Mohamed M, 2020. Case report: COVID-19 masquerading as an acute surgical abdomen. $A m \mathrm{~J}$ Trop Med Hyg 103: 841-843.

6. Sellevoll HB, Saeed U, Young VS, Sandbæk G, Gundersen K, Mala T, 2020. Acute abdomen as an early symptom of COVID-19. Tidsskr Nor Laegeforen 140. doi: 10.4045/ tidsskr.20.0262.

7. Periyakaruppan M, Kumar S, Kandasamy S, Sangaralingam T, Srinivasan S, Thiagarajan A, Ganapathy N, 2020. COVID abdomen: SARS-CoV-2 infection presenting as 'acute abdomen' in a child. Indian J Pediatr 88: 299-300.

8. Noda S, Ma J, Romberg EK, Hernandez RE, Ferguson MR, 2020. Severe COVID-19 initially presenting as mesenteric adenopathy. Pediatr Radiol 51: 140-143.

9. Pazgan-Simon M, Rorat M, Buczyńska I, Zińczuk A, Simon K, 2020. Gastrointestinal symptoms as the first, atypical indication of severe acute respiratory syndrome coronavirus 2 infection. Pol Arch Intern Med 130: 338-339.

10. Saeed U, Sellevoll H, Young V, Sandbæk G, Mala T, 2020. COVID-19 may present with acute abdominal pain. BrJ Surg 107: e186-e187.

11. Wu CY, Yu XP, Ma AHY, Wang LP, Yang NB, Li GX, Shi JJ, Qian $\mathrm{GQ}, 2020$. Coronavirus disease 19 with gastrointestinal symptoms as initial manifestations: a case report. $J$ Int Med Res 48: 300060520952256.

12. FDA, 2014. Impavido Label. Available at: https://www. accessdata.fda.gov/drugsatfda_docs/label/2014/204684s000lbl. pdf. Accessed February 23, 2021.

13. Hakkarainen KM, Gyllensten $H$, Jönsson AK, Andersson Sundell K, Petzold M, Hägg S, 2014. Prevalence, nature and potential preventability of adverse drug events - a population-based medical record study of 4970 adults. Br J Clin Pharmacol 78: 170-183.

14. World Population Review, 2020. Bolivia Population. Available at: https://worldpopulationreview.com/countries/boliviapopulation. Accessed February 23, 2021. 